\title{
Reliability and validity of a questionnaire to measure personal, social and environmental correlates of fruit and vegetable intake in 10-11-year-old children in five European countries
}

\author{
I De Bourdeaudhuij ${ }^{1, *}$, K-I Klepp ${ }^{2}$, P Due $^{3}, C$ Perez Rodrigo ${ }^{4}, M^{2}$ DV de Almeida ${ }^{5}, M_{\text {Wind }}{ }^{6}$, \\ R Krølner ${ }^{3}, C$ Sandvik ${ }^{2}$ and J Brug ${ }^{6}$ \\ 'Department of Movement and Sport Sciences, Ghent University, Watersportlaan 2, B-9000 Ghent, Belgium: \\ ${ }^{2}$ Institute for Nutrition Research, University of Oslo, Norway: ${ }^{3}$ Department of Social Medicine, University of \\ Copenhagen, Denmark: ${ }^{4}$ Unidad de Nutricion Comunitaria, Bilbao, Spain: ${ }^{5}$ Faculdade de Ciências da Nutrição e \\ Alimentação da Universidade do Porto, Portugal: 'Erasmus Medical Center Rotterdam, Department of Public Health, \\ The Netherlands
}

Submitted 5 January 2004: Accepted 17 May 2004

\begin{abstract}
Objectives: To investigate the internal consistency of the scales and the test-retest reliability and predictive validity of behaviour theory-based constructs measuring personal, social and environmental correlates of fruit and vegetable intake in 10-11year-old children.

Design: Test-retest with one-week interval.

Setting: Five European countries: Norway, Spain, Denmark, Portugal, Belgium.

Subjects: Three hundred and twenty-six children completed the questionnaire during class hours.

Results: For the total sample across all countries, the test-retest reliability was good to very good (intra-class correlation coefficient (ICC) $>0.60$ ) for 12 out of the 15 fruit constructs and also for 12 out of the 15 vegetable constructs. Acceptable ICCs, ranging between 0.50 and 0.59 , were found for the remaining constructs. Test-retest reliability was comparable across countries. Only in Portugal were some significantly lower ICCs found for some constructs (knowledge and barriers related to fruit, general self-efficacy related to fruit and vegetables) compared with the other countries. Cronbach's $\alpha$ values were moderate to high (range 0.52 to 0.89 ) with the exception of the general self-efficacy scale, which had a value below 0.50 for both fruit $(\alpha=0.42)$ and vegetables $(\alpha=0.49)$. Spearman correlations with intake ranged between -0.16 and 0.54 for personal determinants and between 0.05 and 0.38 for environmental determinants. Compared with other studies, predictive validity can be considered moderate to good.

Conclusions: The questionnaire provides a reliable, valid and easy-to-administer tool for assessing personal, social and environmental factors of potential influence on fruit and vegetable intake in 10-11-year-olds.
\end{abstract}

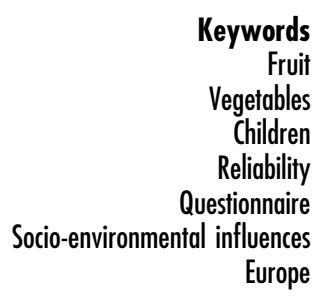

Europe
Epidemiological evidence suggests that regular consumption of fresh fruit and vegetables is associated with lower risks of certain types of cancer, especially cancers of the gastrointestinal and respiratory tracts ${ }^{1,2}$, and a lower risk of heart disease ${ }^{3}$. Furthermore, most fruits and vegetables have a low energy density compared with other foods, and therefore may contribute to weight maintenance ${ }^{4,5}$.

The national guidelines in many countries recommend people of all ages to consume at least five servings of fruit and vegetables per day ${ }^{6}$. However, in most industrialised countries, a considerable percentage of the population does not meet this guideline. This is also true for children. The Health Behaviour in School-Aged Children (HBSC) study investigated fruit and vegetable intake in 11-, 13- and 15-year-olds in 29 countries in their 1997/1998 survey. They found large between-country variation in the prevalence of daily intake of fruit and vegetables. In most countries, $50-70 \%$ of the children reported to eat fruit every day. The results of the 1997/1998 survey also showed a decrease in fruit consumption from the previous survey in 1993/1994 in about two-thirds of the countries. In addition, in almost all countries the proportion of students who eat fruit and vegetables every day decreased with increasing age ${ }^{7}$. Previous studies have also shown that healthy food habits acquired in childhood to a certain extent track into adolescence and adulthood, arguing for 
the promotion of adequate fruit and vegetable consumption especially in schoolchildren ${ }^{8,9}$. Moreover, health habits in children are not as firmly rooted as in adults, which makes them still more amenable to change ${ }^{10}$.

Before designing adequate intervention programmes, information is needed about the factors influencing fruit and vegetable intake. The theoretical frameworks used to study determinants of health-related behaviours are most often derived from social psychology, such as the Theory of Planned Behaviour (TPB) ${ }^{11}$ or the Attitude-Social Influences-Self-Efficacy (ASE) model $^{12}$. Both theories suggest that the most proximal determinant of fruit and vegetable intakes is the intention to eat fruit and vegetables, and that three additional determinants predict intention: attitudes, perceived social influences and perceived behaviour control or self-efficacy. Attitude refers to expectations and evaluations about a given health behaviour. According to the TPB, the subjective norm represents perceived social influences and is defined as the perceived opinion of other people in the direct social environment about the behaviour. The ASE model recognises a broader spectrum of perceived social influences, also including perceived example behaviour of people in the social environment (i.e. modelling or descriptive norms) and perceived direct social support. According to the TPB, the third determinant is the perception as to what extent the behaviour is under personal volitional control (perceived behaviour control; PBC). Environmental and physiological factors are regarded as more distal determinants of behaviour and are expected to influence behaviour via the abovementioned proximal determinants.

The ASE model identifies self-efficacy instead of PBC as the third determinant, which refers to a person's confidence about being able to perform the behaviour. Although these constructs are often measured differently, and some studies have shown unique contributions of self-efficacy and PBC to explaining health behaviour ${ }^{13}$, both constructs are generally regarded to be similar or even identical $^{13,14}$

However, it is uncertain to what extent children's fruit and vegetable intake is determined by the rational decision-making process described above, and research is needed to investigate the determinants of fruit and vegetable intake systematically among children. Some authors have used qualitative methods, such as focus group interviews ${ }^{15-18}$, while others have developed questionnaires to be administered in the classroom ${ }^{19-22}$. Personal factors found to be related to fruit and vegetable consumption in these studies were perceived barriers, skills in preparing fruit and vegetables, self-efficacy, preferences and liking, knowledge, health attitudes and positive outcome expectations. Social factors related to fruit and vegetable intake in children were peer and parental modelling, family and friends' beliefs, parenting control and family connectedness. In addition to personal and social influences, some authors proceeded from a more ecological approach, finding relationships with availability and accessibility of fruit and vegetables in the home, at school and in the neighbourhood ${ }^{23}$.

The consumption of fruit and vegetables among schoolchildren is a complex phenomenon in which personal, social and environmental factors may have mutual influences. Most of the studies cited above included only some of the possible determinants of fruit and vegetable intake, explaining only a (small) part of the variance.

In the present study, a self-administered questionnaire for 10-11-year-olds was developed that was informed by determinant theory as well as these previous studies. The questionnaire included the major personal, social and environmental potential determinants of fruit and vegetable intake. The aims were to investigate the internal consistency of the scales and the test-retest reliability and predictive validity of the constructs measuring personal, social and environmental correlates of fruit and vegetable intake. The study is part of the Pro Children project: a larger study in Europe promoting fruit and vegetable intake in schoolchildren.

\section{Methods}

\section{The Pro Children project}

The Pro Children project aims at promoting and sustaining health through increased vegetable and fruit consumption among European schoolchildren. Nine research centres in nine European countries participate in Pro Children: Austria, Belgium, Denmark, Iceland, The Netherlands, Norway, Portugal, Spain and Sweden. The project consists of two phases. In the first, fruit and vegetable consumption and determinants of consumption levels are assessed in representative samples of schoolchildren in all nine countries; in the second, an intervention programme to increase fruit and vegetable consumption is designed, implemented and evaluated in three of the countries (Norway, The Netherlands, Spain). In both phases, valid methods are needed for the assessment of fruit and vegetable consumption as well as for the assessment of potential determinants of consumption in schoolchildren.

\section{Questionnaire development}

The self-report measure of psychosocial factors related to fruit and vegetable consumption in children had to be:

1. theory-based, including relevant constructs of ruling models in health psychology and health promotion;

2. literature-based, including constructs proved to be related to fruit and vegetable consumption in the past;

3. trans-European, to be used in nine different countries; and

4. brief, easy to read and self-explanatory, to be administered within approximately $30-45 \mathrm{~min}$ in the classroom during school hours. 
The development of the questionnaire was conducted in three steps: a theory- and determinant-oriented literature review; qualitative research; and pre-testing.

\section{Literature review}

To identify determinants of children's fruit and vegetable intake, a major literature review was executed. The review showed that theories or models most often used were Social Cognitive Theory ${ }^{24}$, the Transtheoretical Model/ Stages of Change concept ${ }^{25}$ and the $\mathrm{TPB}^{11}$, and an integration of known models such as the ASE model ${ }^{12}$. The review further showed that the key psychosocial correlates/predictors of fruit and vegetable consumption were: perceived barriers, skills in preparing fruit and vegetables, self-efficacy, peer and parental modelling and beliefs, preferences and liking, knowledge, health attitudes and positive outcome expectations. In addition, some studies included environmental factors such as perceived availability and accessibility of fruit and vegetables at home, school and in society. Furthermore, some studies also found relationships with more general parenting styles and practices, such as family connectedness or authoritative parenting ${ }^{26}$.

\section{Focus group interviews with children}

Psychosocial and environmental determinants that were identified based on theory and literature reviews were further explored and enriched through focus group interviews with children. A protocol was developed to guide the focus groups interviews based on Krueger and Casey $^{27}$. The aims of the focus group interviews were to ensure that certain predictors of fruit and vegetable intake found in the literature review were relevant for our group of 10-11-year-old children, and to find potentially relevant predictors that had not yet been identified in papers from earlier studies. Focus group interviews were conducted in six countries: Belgium, Denmark, The Netherlands, Norway, Portugal and Spain. A total of 234 students participated in 33 focus groups. All focus group interviews were audio-taped and transcribed and checked systematically for information on potential determinants by two members of the research team. Results of these focus group interviews served as the basis for the development of the questionnaire.

\section{Personal interviews with parents and school staff}

In addition to the focus group interviews with children, personal interviews were conducted in the same six countries among parents and school staff according to an interview guide. The interviews were mainly focused on enlightening contextual matters and elements related to fruit and vegetable intake in the daily school and home environment and contextual factors in the school area. Interviews were executed with 53 parents and 33 members of the school staff. Results of these interviews were used further in the development of the questionnaire.

\section{Item selection and testing of the pilot questionnaire}

Based on the theory, literature review and the qualitative data, a draft questionnaire was developed in English in two parallel parts: one part related to fruit intake and an analogue part related to vegetable intake. In all countries the preliminary version of this questionnaire was translated into the local language and discussed with experts, children, parents and teachers, and changes were made based on the comments. After this revision, the 134-item questionnaire was pilot-tested in six countries: Belgium, Denmark, Iceland, Norway, Portugal and Spain. In the pilot test children completed the questionnaire with a member of the research staff present, followed by a group discussion on difficulties, readability, etc. of the different questionnaire items. An exploratory small-scale test-retest procedure was executed in one country (Belgium) to gain some preliminary insight into scale consistency and stability of the items over time. Results of the pilot test showed that some items were too difficult for the children to understand (e.g. some items on selfefficacy), some items were redundant (e.g. habit, social support), and that a construct to assess perceived barriers related to fruit and vegetable consumption was missing. Based on these results, a third version of the questionnaire was constructed consisting of 53 items related to fruit intake and 51 items related to vegetable intake. The questionnaire was first written in English. Subsequently, the questionnaire was translated into the different languages, back-translated into English and checked for inconsistencies. Emphasis was put on achieving equality in meaning across languages.

\section{Final questionnaire}

The final questionnaire used in the present reliability study aimed at measuring 15 constructs that were analogous for fruit and for vegetable intake: self-rated intake, knowledge, attitudes, liking, subjective norm, active parental encouragement, general self-efficacy, intention, habit, preferences, family rules - demands and allowances, availability at home, availability away from home and perceived barriers (see Tables 1 and 2 for an overview of the items, constructs and scaling). First all questions related to fruit intake were asked, followed by those related to vegetable intake. Most concepts were measured by only one or two items due to practical constraints on the length of the questionnaire. Some items included in the final questionnaire are not reported here because internal consistency or test-retest values were too low (e.g. 12 barrier questions were included but only four were retained in the form tested in this actual test-retest).

\section{Fruit and vegetable intake questionnaire}

Usual intake of fruit and vegetables was measured using a food-frequency questionnaire based on the HBSC crossnational study $^{28}$. Children were asked how often they usually eat (1) fresh fruit, (2) salad or grated vegetables, 


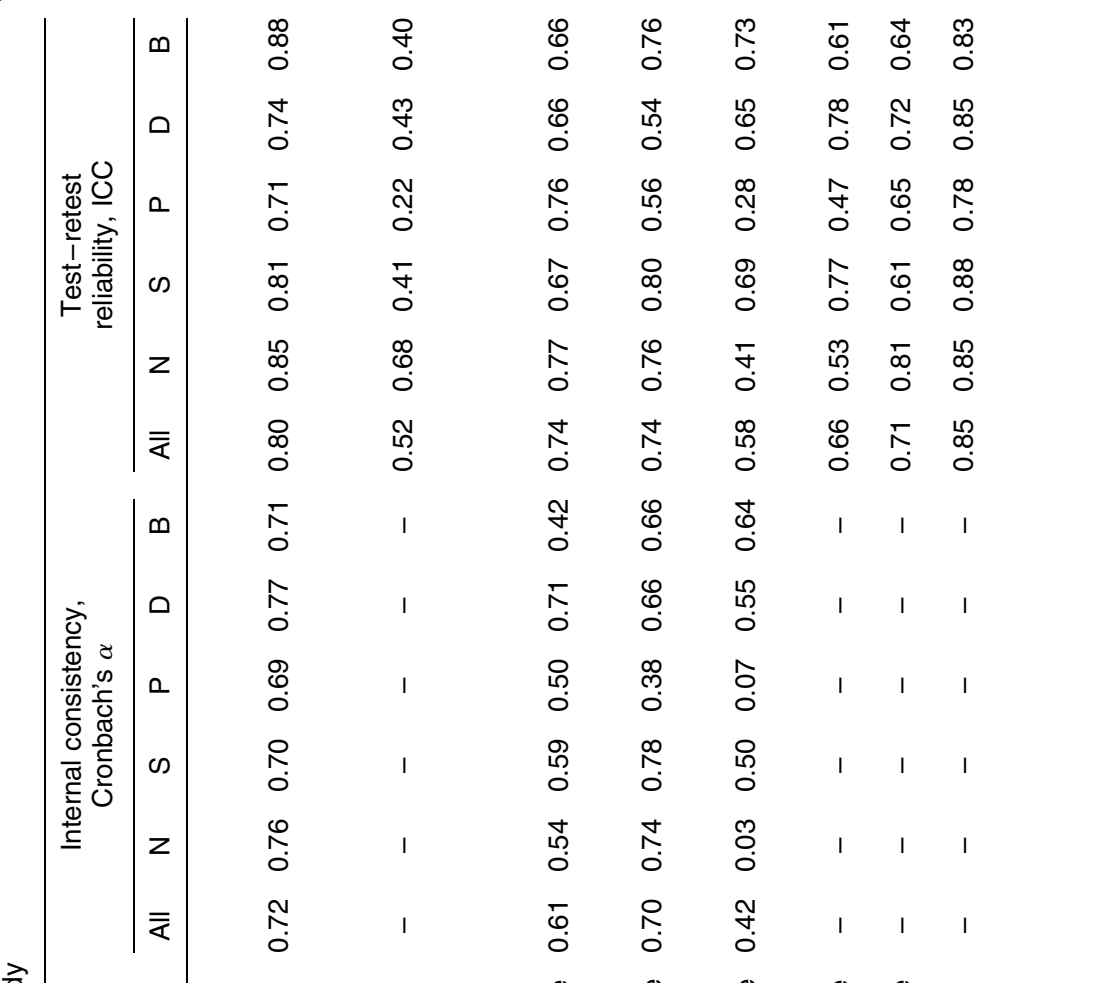

I De Bourdeaudhuij et al. 


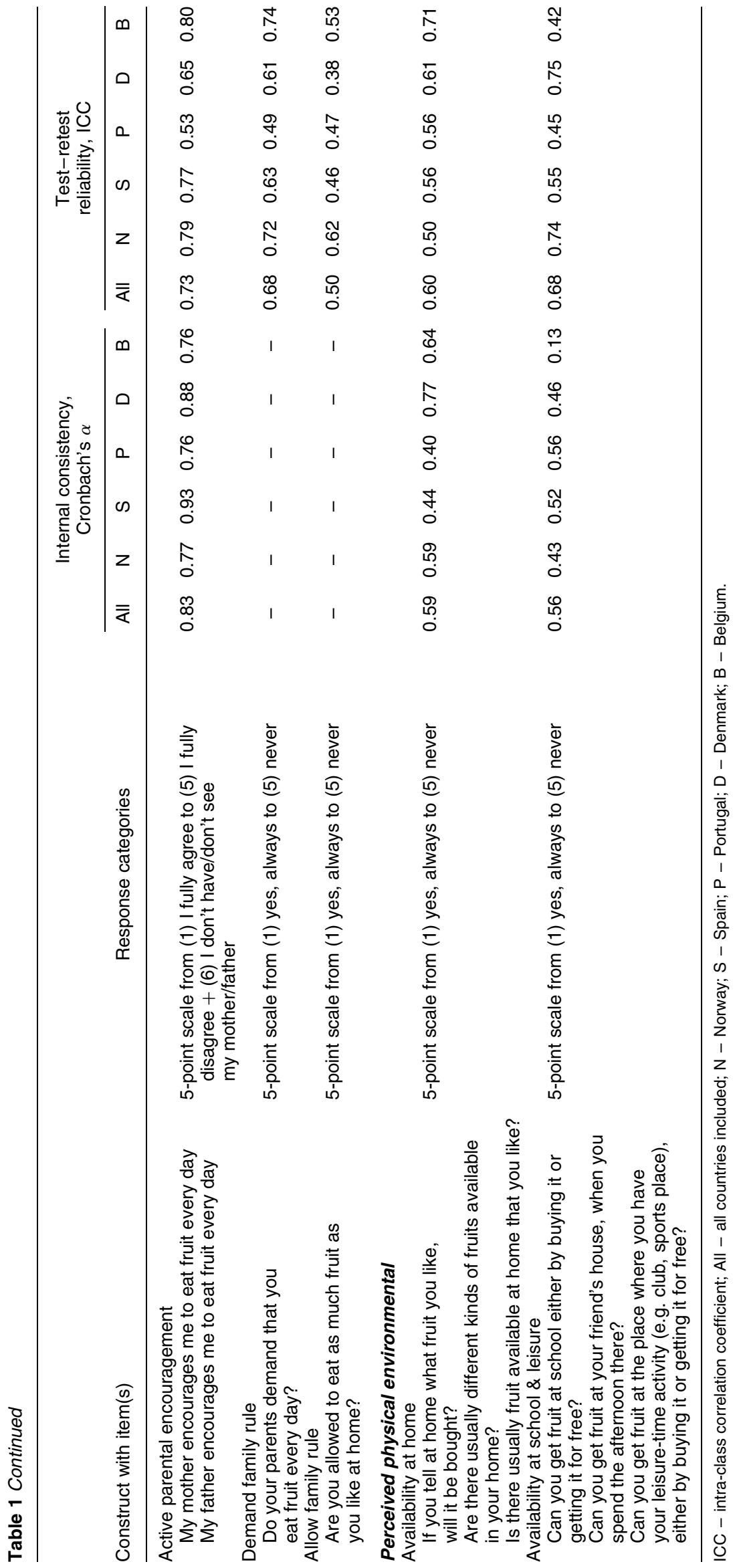




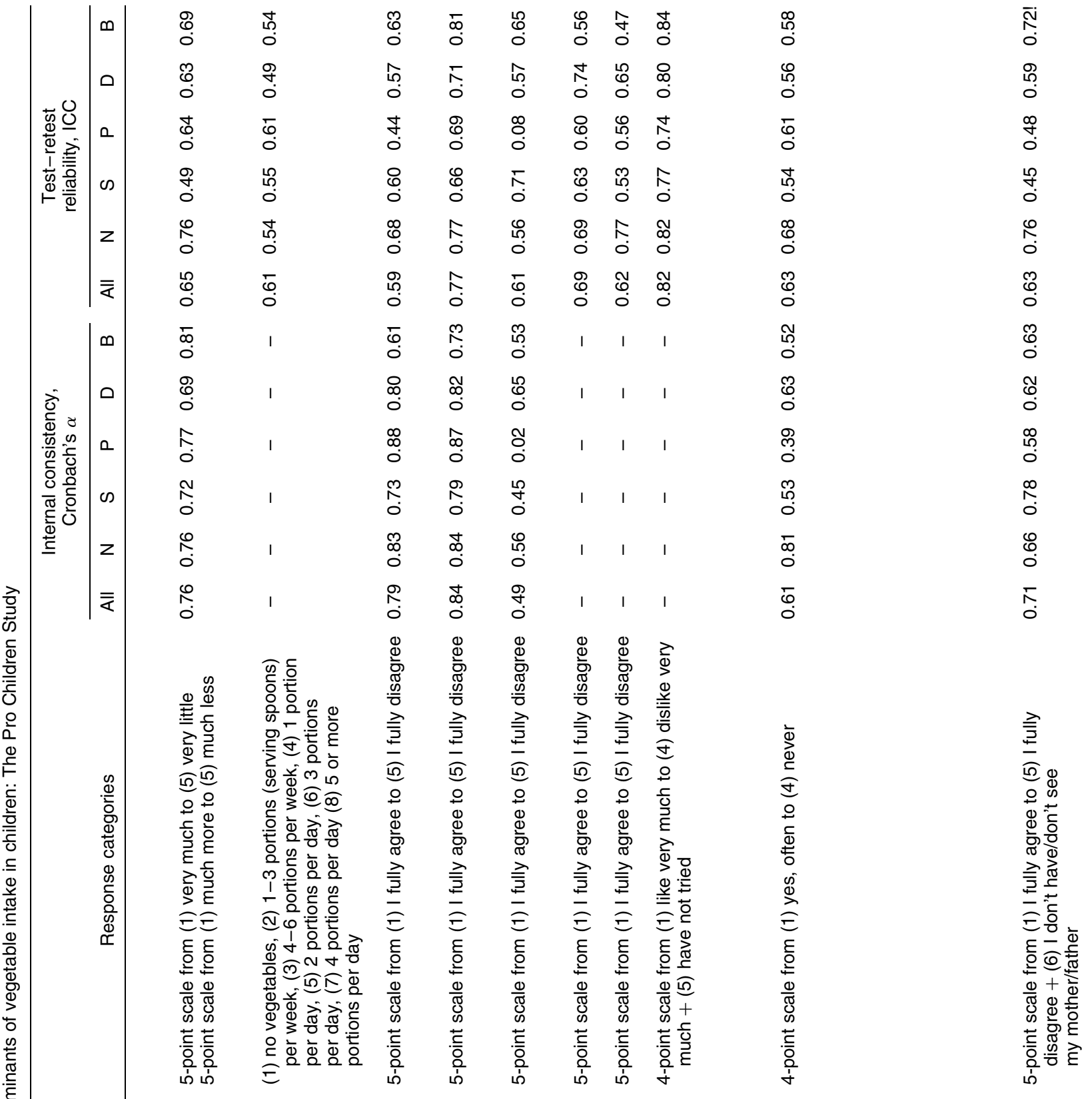

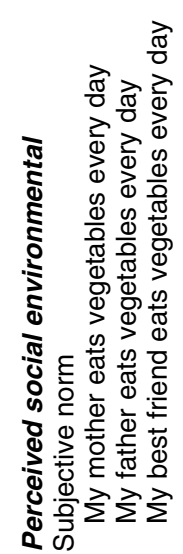


Reliability of correlates of fruit and vegetables

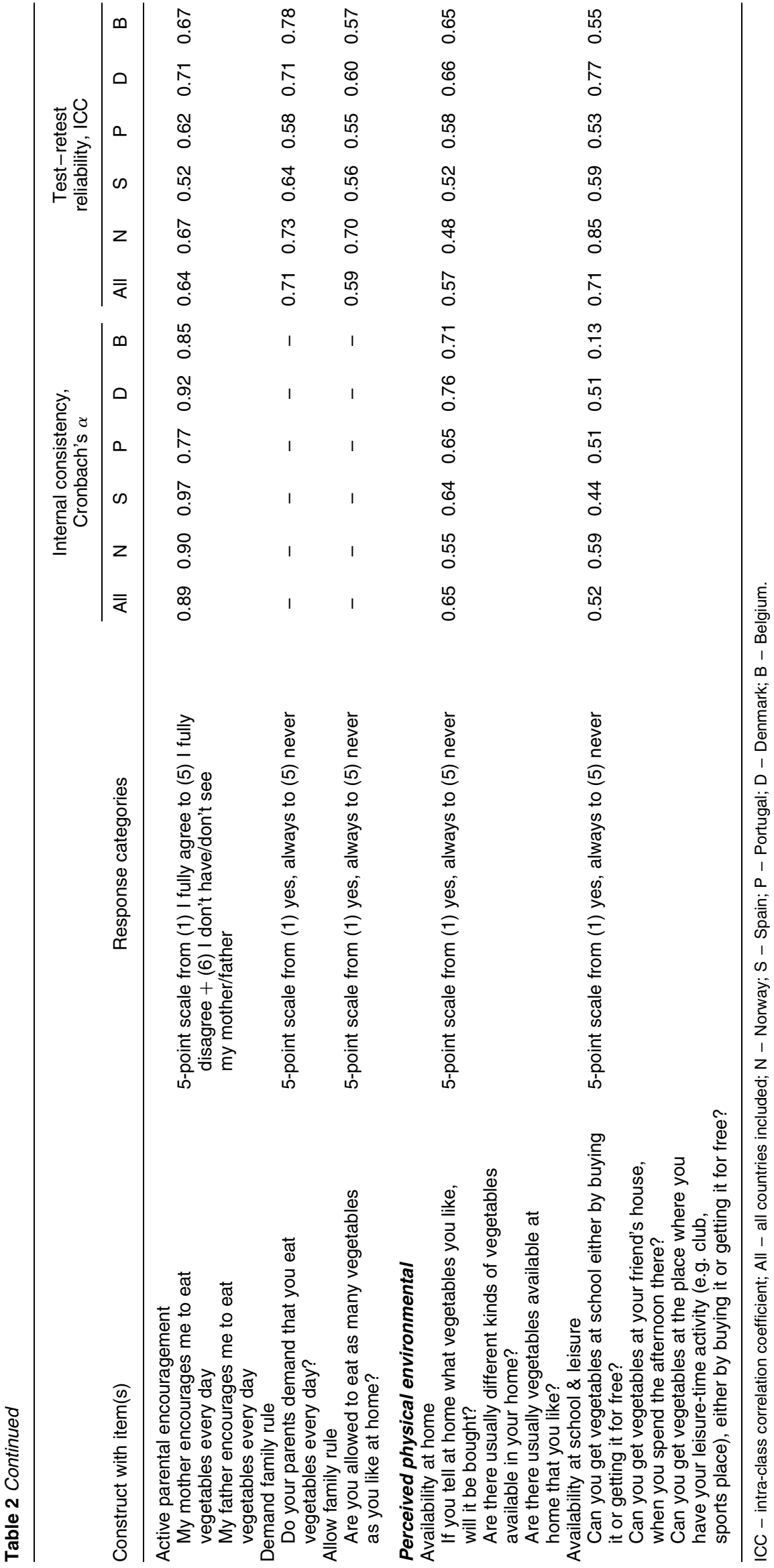


(3) other raw vegetables and (4) cooked vegetables. Response categories were (1) never, (2) less than one day per week, (3) one day per week, (4) 2-4 days a week, (5) 5-6 days a week, (6) every day, once a day, (7) every day, twice a day and (8) every day, more than twice a day. The reliability and validity of these intake measures are described elsewhere ${ }^{29}$.

\section{Sample and procedure}

Five countries participated in the test-retest reliability study: Belgium, Denmark, Norway, Portugal and Spain. A north-south distribution within Europe reflecting main cultural differences was taken into account in selecting these five countries. Classes with children aged 10-11 years (born mainly in 1991 and 1992) were selected in at least two schools per country. The schools were selected to represent areas with different social levels. Of the 361 children invited to participate, 328 (91\%) returned informed consent forms from parents and completed the forms at both times: $76 \%$ in Norway $(n=55), 99 \%$ in Spain $(n=78), 100 \%$ in Portugal $(n=60), 82 \%$ in Denmark ( $n=64)$ and $99 \%$ in Belgium $(n=71)$. Fifty-one per cent of the sample consisted of girls. The data on two children were not included in the analyses because of unavailability of the date of birth or because the child was too old (born in 1989). In the final sample, 22 participants were born in 1990 (7\%), 136 were born in 1991 (42\%) and 168 were born in 1992 (51\%). The questionnaires were administered in the classroom while a member of the research team was present in May-June 2003. Participants filled in two identical questionnaires with a 7- to 12-day interval. Ethical approval for the study was obtained from all participating countries according to national legislation.

\section{Statistical analysis}

Cronbach's $\alpha$ coefficients were computed to measure the internal consistency of the scales. Since the present study explored new measures in children and since most measures included only a few questionnaire items, values of $\alpha$ larger than 0.50 were considered acceptable $\mathrm{e}^{30}$. Single measure intra-class correlation coefficients (ICCs) were used to explore the test-retest reliability with the test-retest interval. Among children, coefficients in the range of $0.60-0.80$ can be considered as reflecting good test-retest reliability, while values ranging from 0.81 to 1.00 are excellent ${ }^{31,32}$. Mean scores were compared between the test and the retest for all fruit and vegetable constructs using paired $t$-tests with Bonferroni correction. Spearman correlations were computed between all fruit and vegetable determinant scales and fruit and vegetable intake to measure predictive validity. Data were analysed using SPSS 11.0 (SPSS Inc., Chicago, IL, USA).

\section{Results}

\section{Internal consistency of scale}

Tables 1 and 2 report Cronbach's $\alpha$ values for the fruit and vegetable scale, respectively. In general, internal consistency was somewhat higher for the vegetable scales than for fruit. In the total sample, $\alpha$ greater than 0.60 was found for four of the nine fruit scales (self-rated intake, attitudes, liking and active parental encouragement), and for seven out of the nine vegetable scales (selfrated intake, attitudes, liking, subjective norm, active parental encouragement, availability at home and perceived barriers). For four of the fruit scales and for one vegetable scale, $\alpha$ ranged between 0.50 and 0.60: subjective norm, availability at home and perceived barriers for fruit, and availability away from home for both fruit and vegetables. The general self-efficacy scale had $\alpha$ below 0.50 for both fruit $(\alpha=0.42)$ and vegetables ( $\alpha=0.49)$.

For most scales, Cronbach's $\alpha$ values were highly comparable across countries. Only small differences were found for the following fruit and vegetable scales: selfrated intake, attitudes, active parental encouragement and availability at home. For the vegetable scales liking and subjective norm results were also comparable across countries, whereas for the respective fruit scales the internal consistency was considerably lower among Portuguese children for liking $(\alpha=0.38)$ and lower among Spanish children for subjective norm $(\alpha=0.36)$. In Belgium, a considerably lower $\alpha$ value ( $\alpha=0.13$ ) was found for availability of fruit and vegetables away from home than in the other countries. Finally, internal consistencies were very diverse for the self-efficacy scales, ranging from close to zero in Norway and Portugal to over 0.60 in Belgium and Denmark for fruit.

\section{Test-retest reliability}

For the total sample, test-retest reliability was good to very good (ICC $>0.60$ ) for 12 of the 15 fruit constructs and also for 12 of the 15 vegetable constructs. The ICCs for the other three constructs all ranged between 0.50 and 0.59 , indicating that no unacceptably low reliability coefficients were detected for the total sample.

As for the internal consistency, the test-retest reliability was mostly comparable across countries. Only one country, Portugal, had significantly lower ICCs than the other countries. The ICCs for the Portuguese children were significantly lower than the total ICCs for knowledge and barriers related to fruit, and for general self-efficacy related to fruit and vegetables ( $90 \%$ confidence interval).

No significant differences in mean scores were found between the test and the retest for all fruit and vegetable constructs, with the exception of self-rated fruit intake. The children perceived a significantly higher fruit intake at the retest $(t=-5.98, P<0.001)$. 


\section{Predictive validity}

Table 3 reports the Spearman correlations between the fruit and vegetable determinant scales and fruit and vegetable intake, respectively. For the total sample, all correlations yielded significance with the exception of the 'allow family rule' for fruit intake. For personal determinants the predictive validity was moderate to good, ranging from -0.20 to 0.54 for fruit and from -0.16 to 0.54 for vegetable intake. Perceived social environmental and physical environmental determinants showed lower predictive validity (0.05 to 0.27$)$, with the exception of modelling (0.32 and 0.38). In general a similar pattern was found across countries. However, some differences were also visible. For example, in Sweden, low correlations were found for the personal determinants and higher correlations for the environmental determinants.

\section{Discussion}

The aims of the present study were to develop and investigate the reliability and predictive validity of a (concise) questionnaire to assess potential determinants related to fruit and vegetable intakes in 10-11-year-old children. The study revealed that the instrument developed to measure personal, social and environmental correlates of fruit and vegetable intakes in schoolchildren showed moderate to good test-retest reliability for all constructs, and moderate to good internal consistency for the scales with the exception of selfefficacy. The predictive validity of the constructs was moderate to good for the personal determinant scales and low to moderate for the perceived social and physical environmental scales. Furthermore, administration of the questionnaire in the school setting among 10-11year-olds proved to be applicable.

Reliability correlations above 0.50 are certainly satisfactory to good in a study population of schoolchildren aged 10-11 years. In earlier studies, test-retest reliabilities have often been found to be lower in questionnaires responded to by children on their own, i.e. in the absence of an adult who could assist the child in responding to the instrument. In schoolchildren, parent reports or self-reports with the aid of parents are often used to solve the problem of low reliability ${ }^{33,34}$. However, the aim of the present study was to develop a completely self-administered questionnaire that could be responded to by children without parental assistance, and which could be used in large-scale surveys across European countries. The observed test-retest reliability scores were quite similar across the participating countries ranging from Iceland and Norway in the north to Portugal and Spain in the south. This means that the same questionnaire can be used reliably among European schoolchildren, maximising comparability. Additional research will be necessary to make the questionnaire more reliable for Portuguese children. It is possible that the Portuguese children have more difficulties in understanding some constructs, leading to contradictory interpretations and lower test-retest reliability. In addition, cultural and social differences among the various groups of children may contribute to these discrepancies. Another explanation could be that Portuguese children are less familiar with filling in questionnaires about correlates of health behaviour than are children in the other participating countries, leading to more inconsistent answers.

Few other studies are available that have measured testretest reliability of psychosocial and/or environmental

Table 3 Predictive validity of scales measuring determinants of fruit and vegetable intake in children (Spearman correlations)

\begin{tabular}{|c|c|c|c|c|c|c|c|c|c|c|c|c|}
\hline \multirow[b]{2}{*}{ Construct } & \multicolumn{6}{|c|}{ Fruit intake } & \multicolumn{6}{|c|}{ Vegetable intake } \\
\hline & All & $\mathrm{N}$ & $\mathrm{S}$ & $\mathrm{P}$ & $\mathrm{D}$ & B & All & $\mathrm{N}$ & $\mathrm{S}$ & $\mathrm{P}$ & $\mathrm{D}$ & $\mathrm{B}$ \\
\hline \multicolumn{13}{|l|}{ Personal } \\
\hline Self-rated intake & $0.54^{\star \star}$ & $0.61^{* *}$ & $0.57^{\star \star}$ & $0.40^{\star *}$ & $0.45^{\star *}$ & $0.58^{\star \star}$ & $0.54^{\star *}$ & $0.67^{\star *}$ & $0.45^{\star *}$ & $0.45^{\star *}$ & $0.43^{\star \star}$ & $0.59^{* *}$ \\
\hline Knowledge & $0.29^{\star \star}$ & 0.26 & 0.22 & $0.37^{\star *}$ & 0.13 & $0.37^{\star \star}$ & $0.29^{\star *}$ & 0.10 & 0.19 & $0.27^{\star}$ & 0.17 & $0.39^{* *}$ \\
\hline Attitudes & $0.27^{\star *}$ & $0.31^{*}$ & 0.22 & $0.29^{*}$ & 0.11 & 0.16 & $0.27^{\star *}$ & $0.47^{\star \star}$ & 0.16 & $0.28^{*}$ & 0.21 & 0.23 \\
\hline Liking & $0.51^{\star \star}$ & $0.48^{\star *}$ & $0.52^{\star *}$ & $0.56^{\star \star}$ & $0.27^{\star}$ & $0.50^{\star \star}$ & $0.52^{\star *}$ & $0.67^{\star \star}$ & 0.15 & $0.61^{* *}$ & $0.29^{*}$ & $0.38^{* *}$ \\
\hline General self-efficacy & $0.42^{\star \star}$ & $0.39^{\star *}$ & $0.52^{\star \star}$ & $0.32^{*}$ & $0.26^{*}$ & $0.41^{\star *}$ & $0.33^{\star *}$ & $0.49^{\star *}$ & 0.03 & 0.16 & $0.43^{\star \star}$ & $0.35^{\star *}$ \\
\hline Intention & $0.41^{\star *}$ & $0.39^{\star *}$ & $0.39^{\star \star}$ & $0.34^{\star *}$ & 0.04 & $0.47^{\star \star}$ & $0.40^{\star *}$ & $0.54^{\star \star}$ & 0.19 & $0.37^{\star \star}$ & $0.32^{*}$ & $0.31^{\star *}$ \\
\hline Habit & $0.52^{\star \star}$ & $0.59^{\star *}$ & $0.33^{\star \star}$ & $0.57^{\star \star}$ & $0.43^{\star \star}$ & $0.60^{\star \star}$ & $0.41^{\star *}$ & $0.55^{\star \star}$ & 0.09 & $0.43^{\star \star}$ & $0.38^{\star \star}$ & $0.44^{\star *}$ \\
\hline Preferences & $0.34^{\star *}$ & 0.23 & $0.34^{\star *}$ & $0.43^{\star *}$ & $0.38^{\star \star}$ & $0.38^{\star \star}$ & $0.51^{\star *}$ & $0.50^{\star \star}$ & $0.23^{\star}$ & $0.69^{\star *}$ & $0.50^{\star *}$ & $0.29^{\star}$ \\
\hline Perceived barriers & $-0.20^{\star \star}$ & -0.26 & $-0.24^{\star}$ & -0.16 & -0.21 & -0.19 & $-0.16^{\star}$ & -0.41 & -0.03 & 0.09 & -0.09 & 0.02 \\
\hline \multicolumn{13}{|l|}{ Perceived social environmental } \\
\hline Modelling & $0.32^{* *}$ & 0.22 & $0.29^{*}$ & $0.33^{\star *}$ & $0.28^{*}$ & $0.34^{\star *}$ & $0.38^{* *}$ & $0.35^{\star}$ & $0.41^{\star *}$ & 0.25 & $0.36^{\star *}$ & $0.41^{* *}$ \\
\hline Active encouragement & $0.17^{\star *}$ & 0.21 & 0.06 & 0.17 & 0.18 & $0.27^{\star}$ & $0.24^{\star *}$ & $0.33^{*}$ & $0.40^{\star *}$ & 0.22 & 0.12 & $0.28^{*}$ \\
\hline Demand family rule & $0.22^{\star \star}$ & $0.29^{*}$ & 0.12 & $0.32^{*}$ & 0.25 & 0.22 & $0.15^{\star}$ & 0.28 & 0.18 & 0.19 & $0.36^{\star \star}$ & $0.35^{\star \star}$ \\
\hline Allow family rule & 0.05 & 0.01 & 0.14 & 0.07 & $0.26^{*}$ & 0.02 & $0.17^{\star \star}$ & 0.14 & 0.15 & $0.27^{*}$ & $0.28^{*}$ & 0.04 \\
\hline \multicolumn{13}{|c|}{ Perceived physical environmental } \\
\hline Availability at home & $0.27^{\star *}$ & 0.18 & $0.35^{\star \star}$ & $0.38^{* *}$ & 0.24 & 0.18 & $0.16^{\star}$ & $0.29^{*}$ & $0.30^{* *}$ & 0.14 & $0.37^{\star \star}$ & 0.04 \\
\hline Availability at school \& leisure & $0.16^{\star *}$ & 0.23 & 0.12 & 0.24 & 0.17 & 0.07 & $0.21^{\star *}$ & -0.06 & 0.22 & 0.20 & 0.03 & 0.21 \\
\hline
\end{tabular}

All - all countries included; N - Norway; S - Spain; P - Portugal; D - Denmark; B - Belgium.

${ }^{*}, P<0.05 ;{ }^{\star *}, P<0.01$. 
correlates of fruit and vegetable intake in children. Moreover, these studies used different scales and constructs and included different and more items, which may bias a fair comparison. Domel et al. ${ }^{19}$ reported testretest Pearson correlations between 0.67 and 0.83 for fruit preferences and between 0.69 and 0.72 for vegetable preferences. In the present study a test-retest ICC of 0.85 was found for fruit preferences, ranging between 0.78 and 0.88 for the five countries, and a test-retest ICC of 0.82 for vegetable preferences that ranged between 0.74 and 0.84 for the five countries. In another study Domel et al. ${ }^{20}$ reported a test-retest correlation of 0.74 for outcome expectations related to fruit and vegetable consumption among 4th- and 5th-grade children. This is in accordance with our results found for the present attitude scale that included two outcome expectations (feeling good and give energy). Cullen et al. ${ }^{22}$ reported test-retest Pearson correlations ranging between 0.19 and 0.75 for different scales measuring family and peer influences on fruit, juice and vegetable consumption in children, which are rather low compared with the values found in the present study. The only available European study among Norwegian 6th graders $^{35}$ reported test-retest correlations ranging from 0.51 to 0.79 . In conclusion, the test-retest reliability of the present questionnaire was comparable or sometimes better than those seen in previously published reports. The slightly older age of our subjects may be responsible for these somewhat better scores, but our stepwise systematic questionnaire development procedure may also be part of the explanation.

The internal consistency of the scales seen in this study was not very high. This may be attributable to the fact that only two or three items were used to measure each construct. Previous studies using more items per scale reported generally higher Cronbach $\alpha$ values $^{19,20,22,35}$. However, these studies mainly focused upon a smaller selection of potential determinants of fruit and vegetable consumption in children ${ }^{19,20,22}$. In questionnaire development there is always a trade-off between precision and extensiveness within potentially important constructs and the wish to include measures of as many potentially important constructs as possible. In the Pro Children Study we chose to include measures of individual, social environmental and perceived physical environmental factors that may influence fruit and vegetable intakes. This meant that most constructs had to be assessed with only a few questionnaire items. On the other hand, we used a stepwise approach to select these items. It is to be expected that including more items per construct would increase the internal consistency of the scales and may also further improve the construct validity of the measurement, but may be expected to be a barrier for school-based administration.

The self-efficacy scale for both fruit and vegetables was the only scale with a low and insufficient Cronbach's $\alpha$ coefficient $(<0.50)$ for the total sample. This scale consisted of two opposite items: 'It is difficult for me to eat fruit/vegetables every day' and 'If I decide to eat fruit/vegetables every day, I can do it'. Before computing the scale, the first item was reversed. The two items succeeded each other in the questionnaire and it is possible that this confused the children and led to inconsistent responses. Problems with this self-efficacy scale were especially prominent in Portugal and Norway. In Belgium, a considerably lower $\alpha$ value was found for availability of fruit and vegetables away from home compared with the other countries. As this suggests that there is only a weak relationship between the three items in that country, the separate items - rather than the composite index - should be used in future studies.

The predictive validity of fruit and vegetable determinant scales was in general moderate to good. For personal determinants the predictive validity ranged from -0.20 to 0.54 for fruit and from -0.16 to 0.54 for vegetable intake. The perceived social environmental and physical environmental determinants showed lower correlations ranging from 0.05 to 0.38 . However, compared with the few studies investigating predictive validity in this age group, the associations in the present study are considerably higher. Other studies reported correlations typically around 0.20 , and not higher than $0.39^{19,20,21,36}$. These correlations can only be considered as a first measure of association between the scales and fruit and vegetable intake. Multivariate model building will be done in a further study including representative samples of all participating countries.

A limitation of the present study is that convenience samples and not representative samples were used in the different countries. In addition, response rates were lower in the northern countries due to fewer completed informed consent forms by the parents. These factors could have affected the interpretation of the results.

We can conclude that the questionnaire provides a reliable and valid tool for assessing personal, social and environmental correlates of fruit and vegetables intake in 10-11-year-olds. This tool is reliable and valid for studying determinants of fruit and vegetable intake and for evaluating nutrition education programmes in this age group.

\section{Acknowledgements}

The project 'Promoting and Sustaining Health through Increased Vegetable and Fruit Consumption among European Schoolchildren' (Pro Children) is funded under the Fifth Framework Programme of the European Commission, thematic programme Quality of Life and Management of Living Resources, key action Food, Nutrition and Health (QLK1-CT-2001-00547).

The Pro Children consortium consists of the following partners: Knut-Inge Klepp (Coordinator), Institute for 
Nutrition Research, University of Oslo, Norway; Carmen Perez Rodrigo, Unidad de Nutricion Comunitaria, Bilbao, Spain; Inga Thorsdottir, Unit for Nutrition Research, Landspitali University Hospital, Reykjavik, Iceland; Pernille Due, Department of Social Medicine, University of Copenhagen, Denmark; Maria Daniel Vaz de Almeida, Faculdade de Ciências da Nutrição e Alimentação da Universidade do Porto, Portugal; Ibrahim Elmadfa, Institute of Nutrition, University of Vienna, Austria; Jóhanna Haraldsdóttir, Research Department of Human Nutrition, Royal Veterinary and Agricultural University, Copenhagen, Denmark; Johannes Brug, Erasmus Medical Center Rotterdam, Department of Public Health, The Netherlands; Michael Sjöström, Unit for Preventive Nutrition, Karolinska Institutet, Stockholm, Sweden; and Ilse De Bourdeaudhuij, Department of Movement and Sport Sciences, Ghent University, Belgium.

The authors wish to thank the following persons for their active participation in the present study: Norway Christina Hildonen, Mona Bjelland; Denmark - Bjørn Holstein, Ida Husby, Mette Rasmussen; Austria - Juergen Koenig; Portugal - Elsa Alves, B Franchini; Sweden Agneta Yngve; Belgium - Lea Maes, Kelly Bobelijn.

\section{References}

1 Key TJ, Allen NE, Spencer EA, Travis RC. The effect of diet on risk of cancer. Lancet 2002; 360: 861-8.

2 Paolini M, Sapone A, Canistro D, Antonelli MA, Chieco P. Diet and risk of cancer. Lancet 2003; 361: 257-8.

3 Trichopoulou A, Lagiou P. Healthy traditional Mediterranean diet: an expression of culture, history, and lifestyle. Nutrition Reviews 1997; 55: 383-9.

4 Lanza E, Schatzkin A, Daston C, Corle DK, Freedman LS, Ballard-Barbasch R, et al. Implementation of a 4-y, highfiber, high-fruit and -vegetable, low-fat dietary intervention: results of dietary changes in the Polyp Prevention Trial. American Journal of Clinical Nutrition 2001; 74: 387-401.

5 Pesa JA, Turner LW. Fruit and vegetable intake and weightcontrol behaviors among US youth. American Journal of Health Behavior 2001; 25: 3-9.

6 World Health Organization (WHO). Diet, Nutrition and The Prevention of Chronic Diseases. Report of a Joint Food and Agriculture Organization/WHO Expert Consultation. Geneva: WHO, 2003.

7 Vereecken C, Maes L. Eating habits, dental care and dieting. In: Health and Health Behaviour among Young People. WHO Policy Series: Health Policy for Children and Adolescents Issue 1. Geneva: WHO, 2000; 83-96.

8 Rozin P. Development in the food domain. Developmental Psychology 1990; 26: 555-62.

9 Kelder SH, Perry CL, Klepp KI, Lytle LL. Longitudinal tracking of adolescent smoking, physical activity, and food choice behaviors. American Journal of Public Health 1994; 84(7): 1121-6.

10 Birch LL. Development of food acceptance patterns. Developmental Psychology 1990; 26: 515-9.

11 Ajzen I, Madden TJ. Prediction of goal-directed behavior: attitudes, intentions, and perceived behavioral control. Journal of Experimental Social Psychology 1986; 22: 453-74.

12 De Vries H, Dijkstra M, Kuhlman P. Self-efficacy: the third factor besides attitude and subjective norm as a predictor of behavioral intentions. Health Education Research 1988; 3: 273-82.

13 Armitage CJ, Conner M. Social cognition models and health behaviour: a structured review. Psychology \& Health 2000; 15(2): 173-89.

14 Conner M, Norman P. Predicting Health Behaviour. Philadelphia, PA: Open University Press, 1996.

15 Baranowski T, Domel S, Gould R, Baranowski J, Leonard S, Treiber $\mathrm{F}$, et al. Increasing fruit and vegetable consumption among 4th and 5th grade students: results from focus groups using reciprocal determinism. Journal of Nutrition Education 1993; 25(3): 114-20.

16 Cullen KW, Baranowski T, Rittenberry L, Olvera N. Socialenvironmental influences on children's diets: results from focus groups with African-, Euro- and Mexican-American children and their parents. Health Education Research 2000; 15(5): 581-90.

17 Kirby SD, Baranowski T, Reynolds KD, Taylor G, Binkley D. Children's fruit and vegetable intake: socioeconomic, adultchild, regional, and urban-rural influences. Journal of Nutrition Education 1995; 27: 261-71.

18 Neumark-Sztainer D, Story M, Perry C, Casey MA. Factors influencing food choices of adolescents: findings from focus-group discussions with adolescents. Journal of the American Dietetic Association 1999; 99: 929-34.

19 Domel SB, Baranowski T, Davis H, Leonard SB, Riley P, Baranowski J. Measuring fruit and vegetable preferences among 4th- and 5th-grade students. Preventive Medicine 1993; 22: 866-79.

20 Domel SB, Baranowski T, Davis HC, Thompson WO, Leonard SB, Baranowski J. A measure of outcome expectations for fruit and vegetable consumption among fourth- and fifth-grade school children: reliability and validity. Health Education Research 1995; 10(1): 65-72.

21 Domel SB, Thompson WO, Davis HC, Baranowski T, Leonard SB, Baranowski J. Psychosocial predictors of fruit and vegetable consumption among elementary school children. Health Education Research 1996; 11(3): 299-308.

22 Cullen KW, Baranowski T, Rittenberry L, Cosart C, Hebert D, deMoor C. Child-reported family and peer influences on fruit, juice and vegetable consumption: reliability and validity of measures. Health Education Research 2001; 16(2): 187-200.

23 Cullen KW, Baranowski T, Owens E, Marsh T, Rittenberry L, deMoor C. Availability, accessibility, and preferences for fruit, $100 \%$ fruit juice, and vegetables influence children's dietary behaviour. Health Education \& Behavior 2003; 30(5): 615-26.

24 Bandura A. Social Foundations of Thought and Action: A Social Cognitive Theory. Englewood Cliffs, NJ: Prentice Hall, 1986.

25 Prochaska J, Velicer W, Rossi J. Stages of change and decisional balance for twelve problem behaviors. Health Psychology 1994; 13: 39-46.

26 Kremers SP, Brug J, de Vries H, Engels RC. Parenting style and adolescent fruit consumption. Appetite 2003; $\mathbf{4 1}(1)$ : 43-50.

27 Krueger RA, Casey MA. Focus Groups: A Practical Guide for Applied Research. Thousand Oaks, CA: Sage Publications, 2000.

28 Currie C, Samdal O, Boyce W, Smith R, eds. Health Behaviour in School-aged Children: a WHO Cross-National Study (HBSC), Research Protocol for the 2001/2002 Survey. Edinburgh: Child and Adolescent Health Research Unit, University of Edinburgh, 2001.

29 Haraldsdóttir J, Andersen LJ, Thórsdóttir I, de Almeida MDV, Gottlieb AS, Bjelland M, et al. Fruit and vegetable intake of schoolchildren in a pan-European context: a methodological challenge. Annals of Nutrition and Metabolism 2003; 47(6): 502. 
30 Nunnally JC. Psychometric Theory. New York: McGraw-Hill, 1967.

31 Sallis JF, Owen H. Physical Activity and Behavioral Medicine. London: Sage Publications, 1999.

32 Kohl HW, Fulton JE, Caspersen CJ. Assessment of physical activity among children and adolescents: a review and synthesis. Preventive Medicine 2000; 31(2): S54-76.

33 Schmidt LJ, Garratt AM, Fitzpatrick R. Child/parent-assessed population health outcome measures: a structured review. Child: Care, Health and Development 2002; 28(3): 227-37.
34 Montoye H, Kemper H, Saris W, Washburn R. Measuring Physical Activity and Energy Expenditure. Champaign, IL: Human Kinetics, 1996.

35 Bere E, Klepp K-I. Reliability of parental and self-reported determinants of fruit and vegetable intake among 6th graders. Public Health Nutrition 2004; 7: 353-6.

36 Gibson EL, Wardle J, Watts CJ. Fruit and vegetable consumption, nutritional knowledge and beliefs in mothers and children. Appetite 1998; 31: 205-28. 